\title{
The Prevalence and Presentation Pattern of Diabetes Mellitus in Patients at Imo State University Teaching Hospital (IMSUTH) Orlu and Imo State Specialist Hospital (IMSSH) Umuguma Owerri (A 10-Year Retrospective Study: $1^{\text {st }}$ November 2004 to $31^{\text {st }}$ October 2013)
}

\author{
Prosper Obunikem Uchechukwu Adogu1 ${ }^{*}$, Henry Nnaemeka Chineke ${ }^{2}$, \\ Morris Uzoma Ewuzie ${ }^{3}$, Okezie Oguamanam Enwere ${ }^{4}$, Nonye Bibiana Egenti ${ }^{5}$ \\ ${ }^{1}$ Department of Community Medicine, Nnamdi Azikiwe University Teaching Hospital, Nnewi, Nigeria \\ ${ }^{2}$ Department of Family Medicine, Imo State University Teaching Hospital, Orlu, Nigeria \\ ${ }^{3}$ Department of Accident and Emergency, Imo State University Teaching Hospital, Orlu, Nigeria \\ ${ }^{4}$ Department of Internal Medicine, Imo State University Teaching Hospital, Orlu, Nigeria \\ ${ }^{5}$ Department of Community Medicine, University of Abuja Teaching Hospital, Abuja, Nigeria \\ Email: Prosuperhealth50@gmail.com
}

Received 25 February 2015; accepted 26 March 2015; published 30 March 2015

Copyright (C) 2015 by authors and Scientific Research Publishing Inc.

This work is licensed under the Creative Commons Attribution International License (CC BY). http://creativecommons.org/licenses/by/4.0/

\section{(c) (i) Open Access}

\begin{abstract}
Background: The rising prevalence of diabetes mellitus imposes great burden on health worldwide. The burden is enormous in terms of pressure on existing human and material health resources. Diabetes is insidious in onset and has many patterns of presentation which often militates against early detection and diagnosis. Thus most patients present late with the exacerbation of symptoms and complications. Objective: To determine the prevalence and pattern of presentation of diabetes mellitus among patients attending Imo State University Teaching Hospital (IMSUTH) Orlu and Imo State Specialist Hospital (IMSSH) Umuguma Owerri, both in Imo State, Nigeria. Methodology: A retrospective study of the prevalence and pattern of presentation of diabetes mellitus. A total of 2028 patients had diabetes mellitus. Using data collection proforma,
\end{abstract}

\footnotetext{
*Corresponding author.
}

How to cite this paper: Adogu, P.O.U., et al. (2015) The Prevalence and Presentation Pattern of Diabetes Mellitus in Patients at Imo State University Teaching Hospital (IMSUTH) Orlu and Imo State Specialist Hospital (IMSSH) Umuguma Owerri (A 10-Year Retrospective Study: $1^{\text {st }}$ November 2004 to $31^{\text {st }}$ October 2013). Journal of Diabetes Mellitus, 5, 49-57. 
information relating to their pattern of presentation such as symptoms and complications, as well as their socio-demography was collected from the case folders. Data were analyzed using SPSS version 17 and results presented in frequency tables and pie charts. Result: A total of 18,912 patients attended the designated hospitals within the period under review, out of which 2028 were diabetic giving a prevalence of 107.2 per 1000 patients (10.7\%). Out of these 2028 diabetic patients studied, $75 \%$ (1521) had onset of the diseases at the age of 40 years and above, while the remaining $25 \%(507)$ had the onset of the diseases before the age of 40 years. The most affected group was in the age range of 51 - 60 years, 585 (28.7\%), while the least affected age group was 1 10 years, $6(0.31 \%)$. The commonest symptom at presentation was polyuria $2028(100 \%)$, followed closely by polydypsia 1939 (95.6\%), while the least presenting symptoms were vaginal discharge and erectile dysfunction $27(1.35 \%)$ respectively. Overall, the symptoms at presentation were polyuria, polydysia, weight loss, fever, blurred vision, paraesthesia, vaginal discharge, erectile dysfunction etc. Conclusion: Diabetes mellitus is a chronic illness with many patterns of presentation ranging from the classical symptoms of polyuria, polydysia, polyphagia and weight loss to the less common ones. The study highlights the need for early detection of the condition through appropriate health information dissemination and institution of prompt and adequate treatment.

\section{Keywords}

Prevalence, Pattern, Diabetes Mellitus, IMSUTH, IMSSH

\section{Introduction}

Diabetes mellitus (DM) is a clinical syndrome characterized by hyperglycemia, polyuria, polydypsia and weight loss [1]. It is a condition in which glucose in the body is not properly utilized. It is either that the insulin is not adequately secreted by the pancreas or that the target cells do not respond to the available insulin in the body or both [2]. Diabetes is as old as mankind. It is one of the non-communicable diseases that affect both the young and old [3].

Smith et al. [3], in 1889 showed that depancreatized dogs developed diabetes. It was then logical to assume that diabetes was simply a hormone deficiency syndrome. This reasoning was strongly reinforced by Edwin et al. [4], when they observed that manifestations of diabetic hyperglycaemia could be promptly resolved by the administration of insulin secreted by the islet cells of Langerhans. There are two main types of diabetes mellitus: type 1 (Insulin dependent) or Juvenile onset and type 2 (Non insulin dependent) [4]. It could also occur in pregnancy and this is referred to as Gestational diabetes mellitus. This can result in increase in both perinatal and maternal morbidity and mortality [5]. Some complications of diabetes mellitus include diabetic foot infections, retinopathy, nephropathy, gastroparesis, non alcoholic fatty liver disease, erectile dysfunction etc. and a general down run in health vitality and longevity [6] [7].

In developing countries such as Nigeria, lots of attention has been focused on the control of infectious diseases in utter disregard of the shifting global disease burden from communicable to chronic non-communicable diseases. This epidemiological transition has increased the public health importance of diabetes mellitus making it to deserve much more than just a passing interest. Unfortunately, because of lack of political will and commitment, low index of suspicion for DM among health workers and ignorance among patients, most developing countries have not generated enough data on the burden of the disease and so effective interventions to reduce diabetes-related morbidity and mortality are not comprehensive [8] [9]. In Nigeria, only few studies have emphasized the contribution of diabetes to the burden of disease in the country, hence diabetes has not attracted the necessary attention required to mobilize resources for its effective control [10].

Apart from health education, early detection by screening remains the panacea for diabetes prevention. However, routine screening for diabetes using urine/blood glucose is rarely done in most healthcare facilities in the country, because most of these lack basic and appropriate technology for the screening, diagnosis, and monitoring of diabetes. Consequently, most diabetic patients present late and often with complications. This situation is made worse by a tendency to resort to traditional healers in search of the elusive cure, and in the erroneous belief that the treatment of the disease lies outside the domain of orthodox medicine. Diagnosis in most cases is an 
incidental finding during a hospital visit. Many diabetic patients lack access to a regular supply of quality antidiabetic medications. Hence, the pattern of diabetes-related morbidity and mortality observed in the country still suggest low access to quality diabetic care services [8] [10] [11].

This study is aimed at highlighting the prevalence and pattern of presentation of diabetes mellitus patients in IMSUTH and IMSSH in Imo state Nigeria. The findings of the study will hopefully help articulate comprehensive preventive measures against diabetes mellitus in Nigeria.

\section{Methodology}

Study Area: The study was conducted at Imo State University Teaching Hospital Orlu and the Imo State Specialist Hospital Umuguma Owerri, both of south east Nigeria. Imo State University Teaching Hospital Orlu is a 250 bedded tertiary health facility and serves as a centre for the training of both paramedical and medical health personnel.

The other study area is Imo State Specialist Hospital, Umuguma in Owerri west Local Government Area. It is also a tertiary health institution which serves as a center for curative and preventive health services as well as a research center. Both hospitals have their catchment areas within Imo State and neighboring states like Anambra, Rivers, and Abia. Both health facilities serve as referral centers for other hospitals and health centers within the catchment areas.

Study Population: This consists of all patients that were treated for diabetes mellitus at both centers from $1^{\text {st }}$ November 2004 to $31^{\text {st }}$ October 2013 (A 10-year retrospective study). This includes both in-patients and outpatients. All the 2028 patients diagnosed from a total patient attendance of 18912 within the time period were studied.

Study Design: It was a retrospective descriptive cross sectional referral hospital-based study of the prevalence and pattern of presentation of diabetes mellitus at Imo State University Teaching Hospital Orlu and the Imo State Specialist Hospital Umuguma Owerri. Records of all patient attendees to the hospital within the specicied 10-year time period were accessed, and the folders of all the diabetic patients diagnosed within the same time period were extracted for more in-depth study of prevalence and pattern of diabetes mellitus.

Data Collection: Data was collected from the extracted folders of diabetic patients using a proforma which contains information on patient's bio-data, socio-demography, family and social history, presenting symptoms and co-morbidities at presentation. Also data was collected on clinical examination findings as well as results of laboratory investigations conducted. Diabetes was diagnosed either by a history of previously known diabetes or fasting blood sugar (FBS) of $\geq 7.0 \mathrm{mmol} / \mathrm{l}[12]$.

Data Analysis: Data collated were entered into an Excel proforma, and the data analyzed using SPSS version 17. Results were presented in frequency tables and pie charts. Standard error of difference between proportions of the socio-demographic variables was expressed z-score and significance level set at $\leq 0.05$.

Ethical Consideration: Approval for the study was obtained from the Ethics and Research Committees of both hospitals prior to commencement of the study.

Limitation of Study: This was the index study of this subject matter at both health facilities; hence there was a dearth of materials on the topic for referencing. This is a hospital-based study in two referral centers and as such the prevalence value for diabetes obtained will expectedly be higher than in the general population.

\section{Results}

A total of 18, 912 patients attended the designated hospitals within the period under review, out of this number, 2028 were diabetic giving a prevalence of 107.2 per 1000 patients $(10.7 \%)$. On the average 200 diabetic patients present in both hospitals per year.

Table 1 shows that diabetes mellitus was higher in males 1056 (52.1\%) than in females 972 (47.9\%). It also showed that the occupational group mostly affected were the retired civil servants 579 (28.5\%), followed by bankers 446 (22\%). Majority of the respondents attained secondary education 858 (42.3\%) followed by tertiary 609 (30\%), while the least was primary education 561 (27.7\%). Sedentary workers recorded higher prevalence of DM than non-sedentary workers $(\mathrm{p}=0.000)$. Similarly, respondents who attained higher (tertiary) education had markedly higher DM prevalence than their counterparts who attained secondary or primary school level $(\mathrm{p}=0.000)$.

Table 2 shows that respondents who had positive history of diabetes mellitus in the family recorded significantly higher DM prevalence of 1875 (92.5\%) than those without a positive family history $153(7.5 \%),(\mathrm{p}=$ 
Table 1. Socio-demographic variables of respondents.

\begin{tabular}{|c|c|c|c|}
\hline Socio demographic variables & Frequency & Percentage (\%) & z-score, p-value \\
\hline \multicolumn{4}{|l|}{ Gender } \\
\hline Female & 972 & 47.9 & \multirow{3}{*}{$\begin{array}{c}Z=1.8 \\
p>0.05\end{array}$} \\
\hline Male & 1056 & 52.1 & \\
\hline Total & 2028 & 100 & \\
\hline \multicolumn{4}{|l|}{ Marital status } \\
\hline Married & 1872 & 92.3 & \multirow{3}{*}{$\begin{array}{c}\mathrm{Z}=47.2 \\
\mathrm{p}=0.000\end{array}$} \\
\hline Single & 156 & 7.7 & \\
\hline Total & 2028 & 100 & \\
\hline \multicolumn{4}{|l|}{ Occupation } \\
\hline Students ${ }^{*}$ & 50 & 2.5 & \multirow{11}{*}{$\begin{array}{c}\text { Sedentary workers }^{* *} \\
\text { Versus } \\
\text { Non-sedentary workers }^{*} \\
\text { Z }=21.6 \\
\mathrm{p}<0.01\end{array}$} \\
\hline Lecturers* & 62 & 3.1 & \\
\hline Traders $^{*}$ & 71 & 3.5 & \\
\hline Hair dressers ${ }^{*}$ & 95 & 4.7 & \\
\hline House wives $^{* *}$ & 161 & 7.9 & \\
\hline Health workers ${ }^{*}$ & 167 & 8.2 & \\
\hline Teachers* & 194 & 9.6 & \\
\hline Farmers ${ }^{*}$ & 203 & 10.0 & \\
\hline Bankers $^{* *}$ & 446 & 22.0 & \\
\hline Retired civil servants $^{* *}$ & 579 & 28.5 & \\
\hline Total & 2028 & 100 & \\
\hline \multicolumn{4}{|l|}{ High level of education } \\
\hline Primary & 561 & 27.7 & \multirow{4}{*}{$\begin{array}{c}\text { Tertiary (higher) education } \\
\text { Versus } \\
\text { Primary or secondary education } \\
\mathrm{Z}=35.3 \\
\mathrm{p}<0.001\end{array}$} \\
\hline Secondary & 858 & 42.3 & \\
\hline Tertiary & 609 & 30 & \\
\hline Total & 2028 & 100 & \\
\hline
\end{tabular}

Table 2. Family-social history, special groups and age at diagnosis of diabetes mellitus.

\begin{tabular}{|c|c|c|c|}
\hline & Frequency & Percentage (\%) & z-score, p-value \\
\hline \multicolumn{4}{|c|}{ History of diabetes mellitus in 1st degree relative } \\
\hline Yes & 1875 & 92.5 & \multirow{3}{*}{$\begin{array}{c}Z=48.1 \\
p=0.000\end{array}$} \\
\hline No & 153 & 7.5 & \\
\hline Total & 2028 & 100 & \\
\hline \multicolumn{4}{|l|}{ Social History } \\
\hline Smokes but do not drink alcohol & 15 & 0.7 & \multirow{5}{*}{$\begin{array}{c}\text { Smoke/drink/or both } \\
\text { Versus } \\
\text { Teetotaler } \\
\mathrm{Z}=31.5 \\
\mathrm{p}<0.001\end{array}$} \\
\hline Drinks Alcohol & 1458 & 71.9 & \\
\hline Drinks and smokes & 321 & 15.8 & \\
\hline Neither smokes nor drinks (Teetotaler) & 234 & 11.5 & \\
\hline Total & 2028 & 100 & \\
\hline \multicolumn{4}{|l|}{ Special groups and age at onset } \\
\hline Pregnant women & 54 & 2.7 & \multirow{5}{*}{$\begin{array}{l}<40 \text { years } \\
\text { Versus } \\
\geq 40 \text { years } \\
Z=23.6 \\
\mathrm{p}<0.001\end{array}$} \\
\hline Children $<18$ years & 6 & 0.3 & \\
\hline$<40$ years (excluding children and women) & 447 & 22 & \\
\hline$\geq 40$ years & 1521 & 75 & \\
\hline Total & 2028 & 100 & \\
\hline
\end{tabular}


0.000). Majority of the respondents consume alcohol 1458 (71.9\%). Thus, alcohol is a strong risk factor for the development of diabetes mellitus. Also, diabetic patients above age 40years of age, 1521 (75\%) had significantly higher prevalence of DM than those less than 40 years, 447 (22\%). Only 54 (2.7\%) pregnant women and 6 $(0.3 \%)$ children presented with DM during the period under review.

Figure 1 shows most common co-morbidity as hypertension 924 (45.6\%).

Table 3 shows the most frequent symptom as polyuria 2028 (100\%) and the most frequent complication is diabetic foot ulcer 213 (10.5) followed by blindness

Also there was more out patient management style 1055 (52\%) than in patient 973 (48\%).

Table 4 shows all the respondents had deranged fasting blood sugar (FBS) and random blood sugar (RBS). FBS was the basis for the confirmatory diagnosis of diabetes mellitus.

Table 5 indicates that the most affected age group was 51 - 60 years 585 (28.7\%). The table shows an increase in prevalence of diabetes with age, peaking at 51 - 60 years age group, followed by a gradual decrease afterwards.

\section{Discussion}

Out of the 2028 respondents studied, 1521 (75\%) were diagnosed of diabetes mellitus at age 40 years and above, while 507 (25\%) were detected at age below 40 years (including children and pregnant women). This is an indication that the prevalence of type 2 diabetes mellitus is probably higher than that of type 1 diabetes, a finding which agrees with that by Kolawole et al. [13], in their study of the epidemiology of diabetes mellitus in Nigerian population. The age group most affected by the ailment was the 51 - 60 years, with the mean age of presentation of 51.5 years and the modal age of 54.2 years while the median age at presentation was 50.3 years. There was a higher prevalence in males 1056 (52.1\%) than in females 972 (47.9\%). This is in keeping with the finding of Adebisi et al. [14], in their study on the prevalence of diabetic patients at risk of developing complications in Ilorin North Central Nigeria.

The socio-demographic data appears to suggest that the occupation and highest educational level attained are some of the determinants of diabetes mellitus. Retired civil servants 579 (28.5\%) and bankers 446 (22\%) were the most affected occupational groups. This can be due to the level of activity carried out by these two groups, most, having a sedentary lifestyle. It may also be due to the fact that these two groups of people reside more in the urban communities, and therefore exposed to westernized pattern of diet and recreation which encourage

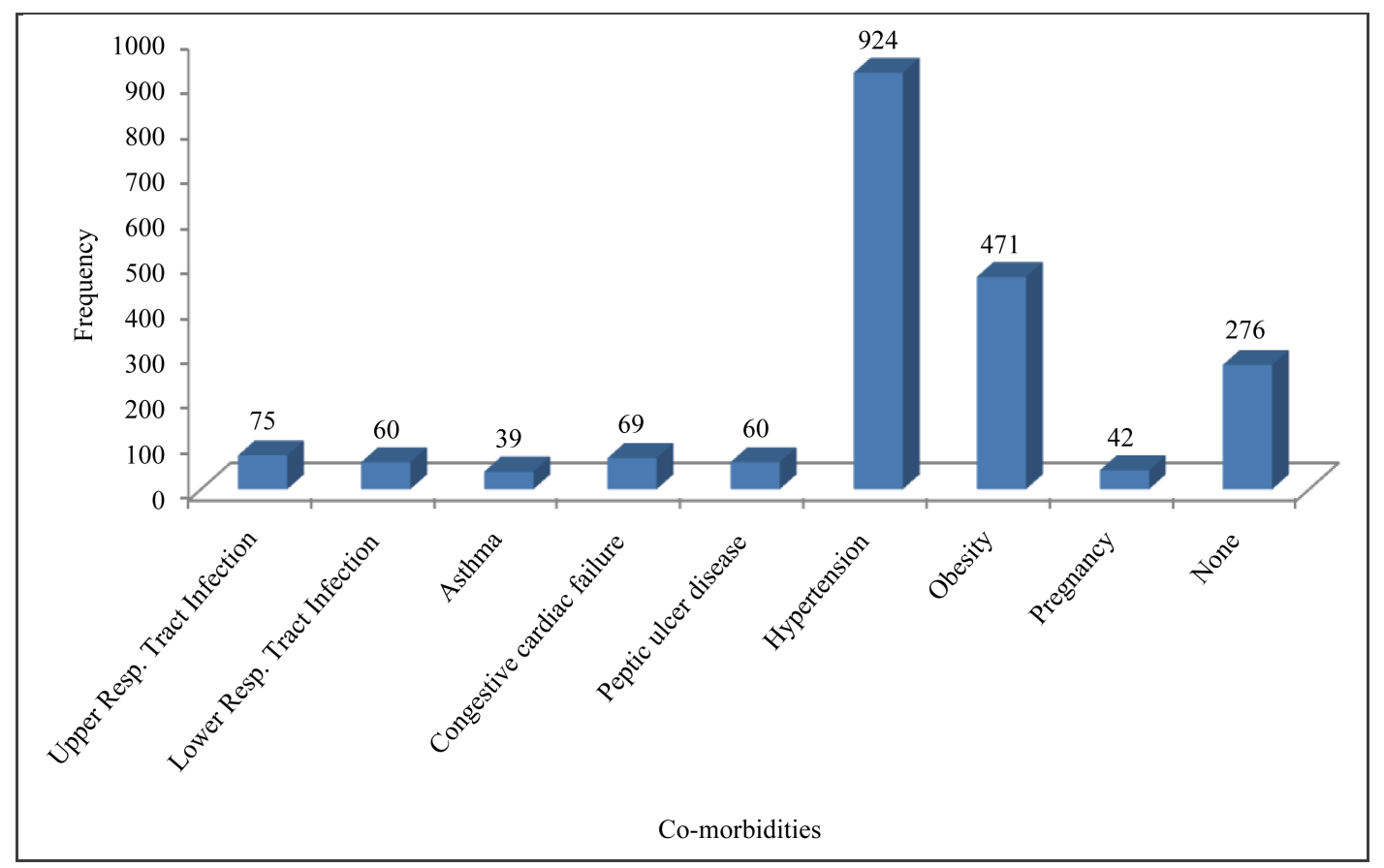

Figure 1. Co-morbidities in the respondents. 
Table 3. Respondents’ presenting symptoms, complications and management pattern.

\begin{tabular}{|c|c|c|}
\hline Variables & Frequency $n=2028$ & Percentage of total \\
\hline \multicolumn{3}{|l|}{ Symptoms } \\
\hline Polyuria & 2028 & 100 \\
\hline Polydipsia & 1959 & 96.6 \\
\hline Weight loss & 735 & 36.2 \\
\hline Polyphagia & 519 & 25.6 \\
\hline Fever & 330 & 16.3 \\
\hline Catarrh/Cough & 174 & 8.6 \\
\hline Dysuria & 156 & 7.8 \\
\hline Unconsciousness & 84 & 4.1 \\
\hline Tiredness & 69 & 3.4 \\
\hline Vaginal discharge & 27 & 1.3 \\
\hline Erectile dysfunction & 27 & 1.3 \\
\hline \multicolumn{3}{|l|}{ Complications } \\
\hline Diabetic foot ulcer & 213 & 10.5 \\
\hline Coma & 57 & 2.8 \\
\hline Sepsis & 174 & 8.6 \\
\hline Stroke & 114 & 5.6 \\
\hline Acute renal failure & 12 & 0.6 \\
\hline Chronic renal failure & 6 & 0.3 \\
\hline Candidiasis & 60 & 3.0 \\
\hline Erectile dysfunction & 159 & 7.8 \\
\hline Blindness (retinopathy) & 201 & 9.9 \\
\hline Gastro paresis & 57 & 2.8 \\
\hline Total with complications & 1055 & 52 \\
\hline \multicolumn{3}{|l|}{ Management pattern } \\
\hline Out patient & 1055 & 52.0 \\
\hline In patient & 973 & 48.0 \\
\hline
\end{tabular}

Table 4. Deranged result of investigations conducted for respondents.

\begin{tabular}{lcc}
\hline Investigation & Frequency & Percentage (\%) \\
\hline Deranged FBS (diagnostic) \& RBS & 2028 & 100 \\
Glycosuria & 1293 & 64.0 \\
Ketonuria & 624 & 30.8 \\
Proteinuria & 111 & 5.5 \\
Deranged S/E/U/C & 1098 & 54.1 \\
Deranged lipid profile & 915 & 45.1 \\
Abnormal Chest X-ray findings & 174 & 8.6 \\
Abnormal ultrasound finding & 156 & 7.7 \\
\hline
\end{tabular}

Key: FBS = Fasting blood sugar; RBS = Random blood sugar; S/E/U/C = Serum electrolyte, urea and creatinine. 
Table 5. Prevalence of diabetes mellitus by age groups.

\begin{tabular}{ccc}
\hline Age Group (in years) & Frequency & Percentage (\%) \\
\hline $1-10$ & 6 & 0.3 \\
$11-20$ & 6 & 0.3 \\
$21-30$ & 135 & 6.7 \\
$31-40$ & 360 & 17.8 \\
$41-50$ & 432 & 21.3 \\
$51-60$ & 585 & 28.7 \\
$61-70$ & 300 & 14.8 \\
$71-80$ & 117 & 5.8 \\
$81-90$ & 75 & 3.7 \\
Above 90 & 12 & 0.6 \\
Total & $\mathbf{2 0 2 8}$ & $\mathbf{1 0 0}$ \\
\hline
\end{tabular}

weight gain, a very important risk factor for type 2 diabetes mellitus [15]. This finding was also observed by Egwim et al. [16], in their study on the relationship between diabetes mellitus and urbanization. The prevalence of diabetes mellitus in Africa is rapidly on the increase especially among urban communities. This can be attributed to the type of food consumed and lifestyle adopted [17].

The prevalence of diabetes mellitus is also related to the level of education attained. It was higher in respondents with secondary level of education than in those with tertiary education. This could be due to a better understanding of the disease by those with tertiary education, better adherence to routine clinic check-up and compliance to treatment.

The family and social history obtained shows that the family history of diabetes mellitus especially in first degree relatives, as well as drinking of alcohol and smoking are important risk factors for developing the disease. Patients with positive family history of diabetes mellitus were 1875 (93.0\%), and significantly higher than those with no family history of the disease 153 (7.5\%). This is in keeping with findings of a study by Kelvin et al. [18], on the genetic basis of diabetes mellitus. Because of the genetic basis of the illness, a family history of diabetes especially in the first degree relative is a strong predisposing factor. Diabetic patients almost always give a history of the father, mother, uncle or siblings being diabetic. Individuals with positive family history of DM or found to possess one or more of the modifiable risk factors as stated earlier need special attention, education and more frequent screening for the disease. The movement toward screening for diabetes in people without symptoms has become increasingly important because of the growing number of cases of undiagnosed diabetes and prediabetes [19].

The most common presenting symptom was polyuria, with a frequency of 2028 (100\%). All the patients have polyuria. This is followed by polydipsia, with a frequency of 1959 (96.6\%). The least common presenting symptoms were vaginal discharge 27 (1.3\%), (seen more commonly in pregnant women) and erectile dysfunction 27 (1.3\%). The above are easily recognizable symptoms which can be exploited to make early diagnosis of the disease and institute prompt and adequate treatment. The diagnosis of the disease on the basis of classical symptoms has since become a relatively simple matter even for the medical student and asymptomatic DM can be diagnosed by the finding of glycosuria in routine urinalysis or an elevated fasting blood sugar values on routine examinations [12].

The most common complication was diabetic foot ulcer 213 (10.5\%), followed by retinopathy 201 (9.9\%). This finding was similar to that of Adebisi et al. [14], which also revealed that diabetic foot ulcer and retinopathy were the most common diabetic complications. Chronic complications are responsible for most illnesses and death associated with diabetes and these usually appear after several years of elevated blood sugars (hyperglycemia). Since patients with type 2 diabetes may have elevated blood sugars for several years prior to diagnosis, these patients may have evidence of complications at the time of diagnosis [20]. It is much better to prevent the onset of diabetic complications than to manage them. Complications can set in if health workers fail to identify high risk groups with a view to educating them, and if there are too many missed opportunities for screening to 
identify prediabetic and symptomatic cases. Even with the onset of the disease, complications can still be prevented by application of some basic principles like taking medications strictly as prescribed by the doctor, close monitoring of blood sugars, following a sensible diet and refusal to skip meals, exercising regularly and religiously keeping appointment with the doctor to monitor for complications [20].

Hypertension was found to be the most common co-morbidity with a frequency of 924 (45.6\%). This finding was similar to that observed by Okafor et al. [15], on the pattern of dyslipidemia among Nigerians with diabetes, which revealed that dyslipidemia and hypertension were the most common co-morbidities in diabetic patients. Comorbidity is the occurrence of one or more chronic conditions in the same person with an index-disease, occurs frequently among patients with diabetes [21]. It has the potential to increase medical care costs for patients with diabetes. Therefore the current single disease management approach is not applicable to a large part of the patients with diabetes in the future, the focus should be on integrated diabetes care programs [22].

All the respondents had deranged fasting blood sugar level greater than $5.5 \mathrm{~mol} / \mathrm{L}$ (or $>126 \mathrm{mg} / \mathrm{dl}$ ) which are the upper limits of the normal values. They also had random blood sugar levels greater than $199 \mathrm{mg} / \mathrm{dl}$ (or 11.0 $\mathrm{mmol} / \mathrm{L}$ ), which are the upper limits of normal. The deranged fasting and random blood sugar levels served as the basis for the diagnosis of diabetes mellitus. Other investigations conducted on the respondents were urinalysis, serum electrolytes, urea, creatinine, and lipid profile which showed varying levels of derangement. All these investigations aid the definitive diagnosis of DM and so should be made available not only at the tertiary health centers but also at the primary health centers as close to 'where people live and work' as possible.

Majority of the respondents 1055 (52\%) were managed as out-patients, while 973 (48\%) were admitted. The large proportion of diabetics managed as in-patients is an indication of the number of such patients who present with substantial and chronic poor metabolic control, and severe chronic complications of diabetes that require intensive treatment or other severe conditions unrelated to diabetes that significantly affect its control [23]. This again underscores the importance of early application of primary prevention and at worst, the institution of secondary prevention strategies.

\section{Conclusion}

Diabetes mellitus is a chronic illness that is commoner in people aged 40 years and above. Its prevalence is rapidly on the rise as a result of urbanization, westernized diet, sedentary lifestyle, obesity and genetic predisposition. It has a lot of complications and co-morbidities especially diabetic foot ulcer, retinopathy and hypertension which have increased the cost of management, morbidity and mortality associated with the disease.

\section{Recommendations}

1) Health workers should be educated enough to pass the right information to the public concerning the pattern of presentation of diabetes mellitus. This will enhance early detection and management.

2) People should be taught about the modifiable risk factors of the ailment such as obesity, sedentary lifestyle, alcoholism and smoking, and then encouraged to adopt healthy life style to prevent the onset of the disease and the development of chronic complications.

3) Government and other stake-holders should demonstrate enough political will and commitment by increased funding, capacity building and provision of necessary materials and equipment at the primary health care level, for early detection and treatment. Where complications and co-morbidities occur, integrated diabetes management approach should be adopted to prevent death and improve the quality of life of the diabetic patient.

\section{References}

[1] Aguocha, B., Ukpabi, J.O., Onyeonoro, U., Njoku, P. and Ukegbu, A.U. (2013) Pattern of Diabetes Mortality in a Tertiary Health Facility in South-East Nigeria. African Journal of Diabetes Medicine, 21, 14-16.

[2] Kelvin, P., Janet, S. and Francine, K. (2007) Management of Type 2 Diabetes in Youth and Adults. American Family Physician, 5, 658-670.

[3] Smith, D., Johnson, M. and Michael, L. (2009) Diabetic Foot Ulcer and Sepsis in Type 2 Diabetes. American Family Physician, 2, 71-72.

[4] Devaseran, D., Edwin, L. and George, S. (2004) Recent Development of Type 1 Diabetes Mellitus. Medi-Link Journal, 3, 22-24. 
[5] Edwin, E. and George, S. (2005) Early Diagnosis and Treatment of Type 2 Diabetes. Medi-Link Journal, 6, 19-21.

[6] Mazen, S. and Bader, R.M. (2008) Diabetic Foot Infection. American Family Physician, 7, 1-3.

[7] Obasi, J., Ibezim, I. and Uka, T. (2005) The Economic Burden of Diabetes in Nigeria. Nigerian Journal of Clinical Practice, 7, 64-65.

[8] Majaliwa, E.S., Elusiyan, B.E., Adesiyun, O.O., et al. (2008) Type 1 Diabetes Mellitus in the African Population: Epidemiology and Management Challenges. Acta Biomedica, 79, 255-259.

[9] Ogbera, A.O., Chinenye, S., Onyekwere, A. and Fasanmade, O. (2007) Prognostic Indices of Diabetes Mortality. Ethnicity \& Disease, 17, 721-725.

[10] Unachukwu, C.N., Uchenna, D.I. and Young, E. (2008) Mortality among Diabetes In-Patients in Port-Harcourt, Nigeria. African Journal of Endocrinology and Metabolism, 7, 1-4.

[11] Chijioke, A., Adamu, A.N. and Makusidi, A.M. (2010) Mortality Pattern among Type 2 Diabetes Patients in Ilorin, Nigeria. Journal of Endocrinology, Metabolism and Diabetes of South Africa, 15, 78-82. http://dx.doi.org/10.1080/22201009.2010.10872231

[12] American Diabetes Association (2004) Diagnosis and Classification of Diabetes Mellitus. Diabetes Care, 33, S62-S69.

[13] Kolawole, B.A., Adeboye, C. and Omotola, J.A. (2007) Epidemiology of Diabetes Mellitus in Nigerian Population. Nigerian Journal of Clinical Practice, 8, 28-30.

[14] Adebisi, S.A., Oghagbon, E.K. and Akande, T.M. (2009) Glycated Haemoglobin and Glycaemic Control of Diabetes in Ilorin. African Journal of Clinical Practice, 3, 87-88.

[15] Okafor, C., Fasanmade, O.A. and Oke, D.A. (2008) Pattern of Dyslipidaemia among Nigerians with Type 2 Diabetes Mellitus. Nigerian Journal of Clinical Practice, 11, 25-31.

[16] Egwim, C., Ukegbu, A.U. and Aguocha, A. (2012) Diabetes Mellitus and Urbanization. African Journal of Diabetes Mellitus, 2, 51-52.

[17] Okon, J. and Martin, J. (2011) The Global Impact of Diabetes Mellitus. African Journal of Diabetes Mellitus, 1, 23-24.

[18] Kelvin, O.A., James, M. and Akinson, U. (2004) Genetic Basis of Diabetes Mellitus. Medi-Link Journal, 5, 40-41.

[19] American Diabetes Association Clinical Practice Recommendations (2013) Standards of Medical Care for Patients with DM. Compliments of Diabetes Education Services, January 2013, Vol. 35, Supplement 1, S11-S63. www.DiabetesEd.net

[20] National Diabetes Information Clearinghouse (2014) Diabetes, Heart Disease, and Stroke. Bethesda.

[21] Beckman, J.A., Creager, M.A. and Libby, P. (2002) Diabetes and Atherosclerosis: Epidemiology, Pathophysiology, and Management. JAMA, 287, 2570-2581. http://dx.doi.org/10.1001/jama.287.19.2570

[22] Struijs, J.N., Baan, C.A., Schellevis, F.G., Westert, G.P. and van den Bos, G.A.M. (2006) Comorbidity in Patients with Diabetes Mellitus: Impact on Medical Health Care Utilization. BMC Health Services Research, 6, 84. http://dx.doi.org/10.1186/1472-6963-6-84

[23] American Diabetes Association (2002) Hospital Admission Guidelines for Diabetes Mellitus. Diabetes Care, 26 , s118. http://dx.doi.org/10.2337/diacare.25.2007.S109 